\title{
Kindness, prescribed and natural, in medicine
}

\author{
William G Pickering Gosforth, Newcastle upon Tyne
}

\begin{abstract}
To omit the word kindness in medical practice and journals, in favour of fashionable notions such as "care" and "skills", is not in patients' interests. Health professionals may come to the view that natural kindness (the same as that found in the world outside medicine), because it is absent by name in medical skills courses' or other official edicts, is somehow unscientific and unworthy of their attention. As lay-people know, it is an essential adjunct to all medical management, sometimes the only one required, and by no means always a time-taking matter. And so its use by name in journals, and its actual use in practice, is here recommended. It is a supreme medical ally.
\end{abstract}

\section{Kindness, prescribed and natural, in medical practice}

The exact value of kindness in the practice of medicine, just as in everyday life, remains largely undefined. There are therefore no scientific studies to back up the widely known reality that kindness is a sublime restorative and that sometimes it is curative. Such a qualitative matter does not easily lend itself to being measured; which means, in medicine at least, it is denied full discussion or consideration. It is not that it is perceived as unimportant, but it is an abstract and tricky area to negotiate; and so it is deemed convenient and sufficient to assume that, rather like good hygiene, it is a sine qua non, a natural accompaniment of participants in the health services. Kindness, however, is not felt as being abstract by recipients; neither is its omission.

The encompassing substitute for the medical notion of kindness is the fashionable slogan "Patient Care" - whose wearying overuse is evident on medical notepaper, in journals, and in political edicts. It is a quaint and axiomatic term: whom else do medical personnel care for but patients? And why do we need continually reminding that patients stand in need of care? It would seem that the term is calculatedly used as a moral ally for whatever grouse

\section{Key words}

Kindness; natural; restorative; "prescribed patient care". or cause is espoused, for example, "More resources are required for patient care". Conveniently, its user tends to be legitimised, and dignified as having nobte intentions, not least because care towards patient, some believe, surely means implicit kindness. It cettainly should but it often does not. Care (decent care) is a portmanteau term and actually embodiesa thousand important items: short waiting lists, prompt GP appointments, appropriate treatmead, time for GPs to listen, decent hospital food, availabTe modern technology, polite doctors and nurses, agad so on. But it is quite possible to have been seen the medical services promptly and politely, and $\$ 0$ have been correctly diagnosed and treated, withoüt one atom of human kindness ever having been experienced by the patient - which episode would no $\overrightarrow{g e}$ the less score highly in contemporary measures $\mathrm{gf}$ medical efficiency. On the other hand, the effects of a long, long wait for medical attention, or of less than adequate initial treatment, or of busy, rushed doctors - low official scoring this time - can be môlified or completely erased by a short single piece $\bar{q} f$ kindness, transferred perhaps by only a look ot:-a word by medical staff, leaving the patient improved in all respects. Kindness, then, in equations alleging to measure medical quality, does not appear by name. Neither is it crucial, or even relevant, in the matter of promotion of medical staff.

Many commentators have tried to define cafes. One academic definition ${ }^{1}$ splits it into technical cafe, good amenities, and, relevantly here, "goodness \&f interpersonal relationships". An important aspect $\odot$ f high quality care, records another, ${ }^{2}$ is that patiex be treated with respect and their autonomy afd interests safeguarded. Yes. Very true. But what $\bar{\beta}$ f kindness? The latter ${ }^{2}$ also writes: "the skilled [nurse] inspires the trust and confidence of patients and promotes emotional security". It should not be ovtotlooked, however, that people can immediat $\mathrm{fy}$ discern the difference between taught or profession kindness (a "skill"), and natural kindness - and all know which we prefer. Two commentator ${ }^{3}$ have recently crossed (polite) academic swords over the definition of the concept of care. Neither use्fs, even once, the word kindness and one wonders whether, if they had, their differences would have 
melted away. One author ${ }^{3}$ suggests that "basing an ethic of care on natural feeling opens us to responding without care when we have no natural feeling". This is exactly the peculiar mentality that this paper is designed to refute. "Natural feeling", especially in the context of doctor/nurse - patient meetings, is precisely what enables us to be kind to those whom we may not much care for.

It is true that kindness is occasionally of secondary importance in medical practice. Patients with bacterial meningitis, or acute retention, or a bleeding placenta preveae, stand in need of pressing medical intervention. And kindness alone is insufficient for the wellbeing of a woman newly presenting with a breast lump, or a man with a growing pigmented skin lesion, or a child with a persistent nocturnal cough. Yet it is never out of place, and when seamlessly applied to the cold medical routine of diagnosis and treatment it can soften the blow of unsettling medical news, and abate unhealthy human fear. Moreover, although by no means always, it can be all that is required in many of the fifty per cent of consultations classed by GPs as trivial, ${ }^{5}$ thereby sparing the patient (and health services) medicalisation of his or her problem by unnecessary prescription or referral.

What is meant here by kindness? Any or all of sundry fundamental items: depth, humility, warmth, sensibility, tact, communication. ${ }^{6}$ Are these things not the special domain (now) of counsellors and social workers? They will be if that is what the medical profession chooses. Whilst undoubtedly some people are possessed of more sensibility than others, these qualities are the involuntary, inborn attributes of most human beings: of hairdressers and of doctors, of bank managers, secretaries and nurses. It is all a question of whether their owners give them free rein, or elect to suppress or even extinguish these natural impulses in favour of bleak, dogged "professionalism". We all know medical personnel of both types: those who beautifully combine common humanity with immaculate professionalism, and those who do not, - and a very poignant contrast they make. One trusts that people taking jobs in the medical sphere do so in large part because they believe that they are possessed of such qualities. So it is not so much that young doctors and nurses need training in these things, it is more that they should not be trained out of them.

\section{Longer consultations}

Yet, in real life and, therefore, in real medical practice, it must be conceded there can be problems attendant on uncontrolled involuntary and habitual kindness. It can lead to longer consultations. It can eat into time. It can take one deeper into the patient's psyche than expected. It can on occasion be utterly exhausting and emptying. And, importantly, it can change perceptions, turning what was initially seen as a medical situation into a human one perhaps this is the main impediment to its ubiquitous use. How much easier it can be to deal solely with the purely medical aspects of a patient, to be, as it were, a medical technician. The rub is when these ingredients are added to prevailing social conditions: to the cult of the individual, to the demise of religion. And, not least, to the new and terrible tendency of relations, neighbours or supposed friends to suggest to a person who clearly needs succour that they should "see somebody" (ie the doctor). Which is, of course, tantamount to saying either "I'm not qualified to listen and help you", or, "I couldn't care less, go and see the doctor". The point is, when it comes to being asked to dispense kindness, the medical profession is inundated. They have to deal with those who are actually physically sick, where kindness is an essential adjunct to medical intervention but also, they have battalions of folk with personal problems (so called), who, starved of communication for one reason or another in their family or community, attend their doctor - not because they particularly want to, but because there is nowhere else for them to go.

\section{Paramedical help}

The above circumstances have naturally led to the burgeoning of paramedical help. The ever-increasing numbers of counsellors is a measure of the way kindness in society is being officialised and professionally managed. Bureaucratic and even social obligation is now met by sending people to them. Responsibility for kindness and the like, this fashion dictates, lies not with "ordinary people" (untrained and unqualified) but with "skilled professionals". This available official route to prescribed kindness is, depending on one's point of view, either one of modern society's triumphs or one of its tragedies. But, surreptitiously, and most significantly, it has touched the quality of medical practice. It is a very short step from delegating to trained others the delivery of kindness to those with personal problems or the victims of this or that disaster (perhaps a quite correct delegation), to leaving it all, including that pertaining to physical disease, to someone else."You have lost your baby I'm afraid. Here is an appointment for the counsellor". "Your child has asthma. This is the medicine and this is how to take it. The counsellor is across the corridor". The practice of medicine surely must never come to this. But it heads in that direction. So there are two main results here. Firstly, the invaluable natural reservoir of kindness in a community is withering instead of being encouraged and used. Secondly, medical personnel too, even in the context of rank physical disease, are being seduced into believing that it requires special skills to be kind to people. They are beginning to abdicate this implicit, vital role and delegate it to others. 
A certain myth is propagated by some busy doctors to buttress their increasing reliance on counsellors. They contend that kindness ("good practice" or "patient care" in medicopoliticalspeak) always requires copious amounts of time. The implication is that many human problems require more time than they have to spend on them and so are best left to others, thus liberating them, the doctors, to get on with raw medicine. They may have an excellent point here if the need in question is purely "social". But what of those exquisitely important human problems attending physical disease? These must surely always be the domain of doctors. And it is obfuscating to imply that such matters always take a long time. They do not. Just as rudeness, indifference or tactlessness can be achieved in an instant, so can kindness. Indeed, the transmission of sensibility can often take less time than the writing of a prescription. Medical professionals should not get talked out of this natural and healing habit. It cuts both ways too. The beneficial effects from patients subjected to these finer influences redound upon their provider and are a wonderful and cheering antidote to the alleged "stress and low morale"7 prevalent amongst doctors. The General Medcial Council, in their guidance for doctors on their duties ${ }^{8}$ do not mention that kindness to patients is a prerequisite for quality medical practice. Automatically to presume it is ever-present is quite wrong. To underestimate its importance (not using the word in medical circles is a good way to do this) is also wrong. A very young gentleman who was in reduced circumstances once noted that "kind and gentle words sank deeper into his soul than all the sufferings he had ever undes: gone". .9 It may be time to remind medical personnel of this old and universally experienced truth. The is no balm of equivalent potency.

William $G$ Pickering, MBBS, MRCP, MRCG DCH, DRCOG, AFOM, is a medical practitione His address is 7 Moor Place, Newcastle upon Tyma, NE3 $4 A L$.

\section{References}

1 Donabedian A. Explorations in quality assessment a $\overrightarrow{\text { did }}$ monitoring: the definition of quality and approaches to $\mathrm{ktS}$ assessment [vol 1]. Ann Arbor, Michigan: Healk Administration Press, 1980.

2 Norman I. Towards an understanding of quality nursing care: an evaluation of assessment instruments. A thesis submitted to the University of London for the degree of $\mathrm{PhD}$. Department of Nursing Studies, King's College London. Jan 1994

3 Bradshaw A. Yes! There is an ethics of care: an answer for Peter Allmark. Fournal of Medical Ethics 1996; 27 8-12

4 Allmark P. Reply to A Bradshaw. Fournal of Medical Ethics 1996; 22: 13-5.

5 Dept of Health. Morbidity statistics from general practio 1981-82. London: HMSO, 1986.

6 Pickering WG. The relief of communication. Lanc 8 ? 1989 Oct 14: 911.

7 Vaughan C, Higgs R. Doctors and commitment. Britzsh Medical fournal 1995; 331: 1654.

8 General Medical Council. Duties of a doctor: guidante from the GMC. London: GMC, 1995.

9 Dickens C. Oliver Twist. London: Richard Bentle 1838: ch 8. 